\title{
Perspectives on epigenetic-based immune intervention for rheumatic diseases
}

Steven G Gray*

\begin{abstract}
Rheumatic disease can loosely be described as any painful condition affecting the loco-motor system, including joints, muscles, connective tissues, and soft tissues around the joints and bones. There is a wide spectrum of rheumatic diseases, many of which involve autoimmunity, including systemic lupus erythematosus and rheumatoid arthritis. A significant body of evidence now links aberrant epigenetic regulation of gene expression with rheumatic disease and points toward the use of epigenetic targeting agents as potential new treatment options, particularly for those conditions associated with an autoimmune element. In this perspective, I will briefly cover the current knowledge surrounding this area in the field of rheumatology.
\end{abstract}

\section{Introduction}

Rheumatic disease involves a diverse number of painful disorders affecting joints, muscles, connective tissues, and soft tissues around the joints and bones, many of which have an autoimmune component. Currently, the American College of Rheumatology lists 30 rheumatic diseases and 12 rheumatic conditions [1]. Rheumatic disease contributes significantly to population health burden. For example, rheumatoid arthritis (RA) affects nearly $1 \%$ of the world population and is a significant cause of disability [2].

Epigenetics originally invoked the notion of stable and heritable gene expression changes that are not due to changes in the primary DNA sequence. Two levels of epigenetic gene regulation can now be envisaged: the classic form involving stable heritable changes and enhanced epigenetic modifications, which can be regarded

*Correspondence: sgray@stjames.ie

Department of Clinical Medicine, Trinity Centre for Health Sciences, Room 2.103, Institute of Molecular Medicine, St James's Hospital, Dublin 8, Ireland as regulatory mechanisms orchestrating inducible responses at the cellular level which may or may not be heritable. Current epigenetic mechanisms involve the following: DNA CpG methylation, histone post-translational modifications (PTMs), histone variants, and noncoding RNA (ncRNA). Aberrant epigenetic regulation of gene expression is now known to be important in the pathogenesis of various diseases, including cancer [3]. Aberrant epigenetic regulation is also implicated in the pathogenesis of many autoimmune inflammatory conditions, including diabetes (reviewed in [4]) and neurodegenerative disease (reviewed in [5]).

An increasing body of evidence links aberrant or altered epigenetic regulatory mechanisms with the pathogenesis of many rheumatic disease states, raising the possibility that epigenetic targeting therapies may have a potential role in the management of these conditions. This review considers recent advances in this area and provides an overview of the potential utility of epigenetic targeting agents in the treatment of rheumatic disease.

\section{DNA methylation changes in rheumatic disease}

The link between aberrant DNA methylation and altered gene expression was first established in studies on cancer [6]. Altered DNA methylation also occurs in rheumatic conditions, such as systemic lupus erythematosus (SLE), and other autoimmune conditions (reviewed in [7-9]).

The study of twins is emerging as an important tool for identifying epigenetic effects in disease. Several such studies have identified altered DNA methylation patterns in SLE and dermatomyositis but not in RA [10]. The genes for which a loss of DNA methylation was observed included several genes associated with immune function, and this loss of DNA was correlated with increased gene expression levels [10]. A study involving global genomewide DNA CpG methylation analysis in $\mathrm{CD}^{+} \mathrm{T}$ cells from patients with SLE identified regions of hypomethylation $(\mathrm{n}=236)$ and hypermethylation $(\mathrm{n}=105)$ [11]. The regions identified revealed that important pathways such as CDK5, PTEN, and insulin receptor signaling were among hypomethylated genes, and the regions also identified specific gene loci (RAB22A, STX1B2, LGALS3BP, DNASE1L1, and PREX1) where methylation 
Table 1. Aberrant epigenetic machinery in rheumatoid arthritis and systemic lupus erythematosus

\begin{tabular}{|c|c|c|c|c|c|}
\hline Enzyme & Alternative symbol & Observation & Disease setting & Cell type & Reference \\
\hline \multirow[t]{2}{*}{ DNMT1 } & & Decreased & SLE & WBCs & {$[10,12,13]$} \\
\hline & & & $\begin{array}{l}\text { SLE } \\
\text { RA }\end{array}$ & $\mathrm{CD}^{+} \mathrm{T}$ cells & [15] \\
\hline DNMT3B & & Decreased & SLE & WBCs & [10] \\
\hline KAT2B & PCAF & Increased & SLE & PBMCs & [28] \\
\hline KAT3A & $\mathrm{CBP}$ & Decreased & SLE & $\mathrm{CD}^{+} \mathrm{T}$ cells & [27] \\
\hline KAT3B & P300 & Decreased & SLE & $\mathrm{CD}^{+} \mathrm{T}$ cells & [27] \\
\hline \multirow[t]{3}{*}{$\mathrm{HDACl}$} & & Increased & SLE & PBMCs & [20] \\
\hline & & & & FLSS & [21] \\
\hline & & Decreased & FLS & Synovial tissues & [22] \\
\hline HDAC2 & & Decreased & SLE & $\mathrm{CD}^{+} \mathrm{T}$ cells & [27] \\
\hline HDAC4 & & Altered sumoylation & RA & FLSS & [23] \\
\hline HDAC7 & & Decreased & SLE & $\mathrm{CD}^{+} \mathrm{T}$ cells & [27] \\
\hline HDAC9 & & Increased & SLE & $\mathrm{CD}^{+} \mathrm{T}$ cells & [24] \\
\hline SIRT1 & & Increased & SLE & $\mathrm{CD}^{+} \mathrm{T}$ cells & [27] \\
\hline KMT? & SETD6 & Decreased & $\begin{array}{l}\text { RA } \\
\text { JIA }\end{array}$ & PBMCs & [26] \\
\hline KMT1B & SUV39H2 & Decreased & SLE & $\mathrm{CD}^{+} \mathrm{T}$ cells & [27] \\
\hline \multirow[t]{2}{*}{ KMT6 } & $\mathrm{EZH} 2$ & Decreased & SLE & $\mathrm{CD}^{+} \mathrm{T}$ cells & [27] \\
\hline & & Increased & RA & FLSS & [25] \\
\hline KDM6B & JMJD3 & Decreased & SLE & $\mathrm{CD}^{+} \mathrm{T}$ cells & [29] \\
\hline
\end{tabular}

CBP, CREB-binding protein; DNMT, DNA methyltransferase; EZH2, enhancer of Zeste, Drosophila, Homolog 2; FLS, fibroblast-like synoviocyte; HDAC, histone deacetylase; JIA, juvenile idiopathic arthritis; JMJD3, Jumonji domain-containing protein 3; KAT, K-acetyltransferase; KDM6B, lysine-specific demethylase 6B; KMT, K-methyltransferase; PBMC, peripheral blood mononuclear cell; PCAF, p300/CBP-associated factor; RA, rheumatoid arthritis; SETD6, SET domain containing 6; SIRT1, Sirtuin 1; SLE, systemic lupus erythematosus; SUV39H2, suppressor of variegation 3-9, Drosophila, Homolog of, 2; WBC, white blood cell.

levels correlated with SLE disease activity [11]. Other studies in patients with SLE have confirmed the increased hypomethylation/decreased DNA methyltransferase 1 (DNMT1) levels [12,13] (Table 1), suggesting that DNA CpG hypomethylation may be a critical element in SLE pathogenesis. In contrast, higher transcript levels of the methyl-binding proteins methyl-CpG-binding domain protein 2 (MBD2) and methyl CpG-binding protein 2 (Mecp2) and decreased expression of MBD4 have also been reported for patients with SLE [13].

Fibroblast-like synoviocytes (FLSs) contribute to the pathogenesis of rheumatic arthritis (RA) by producing inflammatory mediators and contributing to cartilage damage. A DNA methylome analysis comparing FLSs from patients with RA versus patients with osteoarthritis (OA), a non-autoimmune rheumatic disease, has just been reported [14]. In this study, distinct methylation profiles of OA and RA FLSs involving 1,859 differentially methylated (DM) loci located in 1,206 genes were identified, and the two types of FLS could be distinguished solely on the basis of methylation. Further analysis identified 207 genes with multiple hypermethylated or hypomethylated loci. Of these, many were found to play key roles in inflammation, matrix regulation, leukocyte recruitment, and immune responses. Gene expression levels correlated with methylation status, with high expression in hypomethylated genes in RA FLSs and normal expression in genes that were not DM [14]. Levels of DNMTs were recently examined in FLSs from patients with RA and OA [15]. In this regard, resting levels of DNMT1, -3a, and -3b mRNA were similar in RA and OA FLSs, and Western blot analysis showed abundant DNMT1 and DNMT3a protein (Table 1). When RA and OA FLSs were subjected to a pro-inflammatory cue (interleukin-1, or IL-1), rapid decreases of DNMT1 and DNMT3a mRNA occur in these FLSs within 2 to 8 hours of stimulation. Indeed, in OA FLSs following stimulation, demethylation occurred at a CHI3L1 locus (also hypomethylated in RA FLSs) [15].

A genome-wide analysis of DNA CpG methylation has also been performed on $\mathrm{CD}^{+}{ }^{+} \mathrm{T}$ cells from juvenile idiopathic arthritis (JIA) subjects and controls [16]. In the initial analysis of patients, 145 DM loci were identified. However, methotrexate was found to be a confounding issue, and when this was taken into account, the number of DM loci dropped to 11 . Hypomethylation 
at one of these loci, the pro-inflammatory cytokine IL-32, was subsequently confirmed in a validation cohort [16].

Aberrant DNA CpG methylation has now been identified as a causative factor in the increased expression of matrix metalloproteinase-13 (MMP-13), a key protein involved in the degradation of type II collagen within the cartilage [17]. Clearly, aberrant DNA CpG methylation plays an important role in the development of rheumatic disease. One of the central features that are beginning to emerge is the downregulation of DNMT1. This DNMT is considered to be the key maintenance methyltransferase in mammals and therefore responsible for maintaining key methylation patterns at important genes. Loss of DNMT1 activity, therefore, would lead to reduced methylation or hypomethylation at critical CpG residues in loci, and this is borne out by the fact that hypomethylation appears to be more predominant than hypermethylation in global methylation studies. Restoring DNMT1 levels, therefore, may be an important therapeutic strategy in the future. In a subsequent section, I discuss how specific microRNAs (miRNAs) have been shown to regulate DNMT1 and how these particular miRNAs are found to be upregulated in SLE and RA.

\section{Histone-modifying enzymes in rheumatic disease}

The 'histone code' is a well-established hypothesis describing the idea that specific patterns of post-translational modifications to histones act like a molecular 'code' recognized and used by non-histone proteins to regulate specific chromatin functions. These modifications include acetylation, methylation, phosphorylation, sumoylation, and ubiquitination, and various families of proteins which function to place or remove these PTMs have been identified. The best studied of these families are the Kacetyltransferases (KATs), histone deacetylases (HDACs), K-methyltransferases (KMTs), and K-demethylases (KDMs).

KATs, also known as histone acetyltransferases or lysine acetyltransferases, function to covalently add acetyl groups to lysine residues on proteins. KMTs add methyl groups to lysine residues as mono-, di-, or tri-methylation, whereas HDACs and KDMs remove these respective modifications. These PTMs play important roles on many proteins in addition to histones and, in fact, may involve a 'protein code'. A recent estimate using 13 frequent PTM types in eight eukaryotes derived a global network that in humans alone comprises more than 50,000 residues in about 6,000 proteins $[18,19]$.

Within the context of rheumatic disease, strong evidence links the aberrant expression of these families of proteins with disease progression. However, much of the evidence is often conflicting. For instance, increased expression of HDAC1 mRNA has been observed in RA FLSs [20] and in the peripheral blood mononuclear cells
(PBMCs) of patients with RA [21] (Table 1). Conversely, HDAC activity in synovial tissues from patients with RA was found to be approximately twofold lower than that in synovial tissues from patients with OA or from normal controls [22]. Sumoylation of HDAC4 may prove to be an important element in the pathogenesis of RA (Table 1). Critically, levels of the SUMO-specific protease SENP1 have been shown to be decreased, whereas levels of SUMO-1 have been shown to be increased in RA FLSs. Loss of SENP1 is associated with both increased histone acetylation and expression from the MMP-1 promoter. If levels of SENP1 are increased by overexpression, levels of promoter acetylation and MMP-1 expression are decreased, leading to accumulation of HDAC4 at the MMP-1 promoter. Critically, if HDAC4 was knocked down by small interfering RNA (siRNA), SENP1 overexpression was unable to affect the expression of MMP-1 [23]. HDAC9 has been suggested to function as an epigenetic switch in effector $\mathrm{T}$ cell-mediated systemic autoimmunity. Overexpression of HDAC9 has been observed in $\mathrm{CD}_{4}{ }^{+}$subsets of $\mathrm{T}$ cells from both humans and MRL/lpr mice, and abrogation of HDAC9 led to decreased lympho-proliferation, inflammation, and autoantibody production in a murine SLE model with associated survival benefit [24] (Table 1).

KMT6 (EZH2) is a K-methyltransferase and is the catalytic subunit of the polycomb-repressive complex 2 (PRC2), responsible for the methylation of lysine 27 on histone H3 (H3K27) from mono- through trimethylation. KMT6 was recently shown to be overexpressed in RA FLSs [25] (Table 1), and this may result in elevated levels of H3K27me3, a histone post-translational modification associated with RA autoantibodies (discussed in more detail in a subsequent section). In addition, levels of a novel KMT called SETD6 have been shown to be decreased in the PBMCs of patients with RA or JIA compared with controls [26].

Globally, acetylation at histones $\mathrm{H} 3$ and $\mathrm{H} 4$ was found to be hypoacetylated in active CD4 $4^{+} \mathrm{T}$ cells from SLE patients compared with controls [27], whereas global histone H3K9 hypomethylation was a feature in both active and inactive lupus $\mathrm{CD}^{+} \mathrm{T}$ cells compared with controls [27]. When the expression of various epigeneticmodifying enzymes was examined, levels of Sirtuin 1 (SIRT-1) mRNA were significantly increased, whereas levels of KAT3A (CBP), KAT3B (P300), HDAC2, HDAC7, KMT1B (SUV39H2), and KMT6 (EZH2) were significantly downregulated in $\mathrm{CD} 4^{+} \mathrm{T}$ cells from patients with active lupus compared with controls [27]. Validations of these changes have been observed for KAT3A, KAT3B, HDAC7, and SIRT-1 in a murine model of SLE [27], whereas levels of KAT2B (PCAF) have been shown to be elevated in patients with SLE [28] (Table 1).

Aberrant regulation of gene expression by KDM6B (JMJD3) has also been implicated in the development of 
SLE (Table 1). By analyzing available chromatin immunoprecipitation (ChIP) array data, Lu and colleagues [29] determined that there was a greatly enhanced level of histone $\mathrm{H} 3$ lysine 27 trimethylation (H3K27me3) at the hematopoietic progenitor kinase 1 (HPK1) promoter of SLE CD $4^{+} \mathrm{T}$ cells relative to controls. The product of this gene negatively regulates $\mathrm{T}$ cell-mediated immune responses. As a consequence of this histone methylation, HPK1 mRNA and protein levels were significantly decreased in $\mathrm{CD}^{+} \mathrm{T}$ cells of patients with SLE, thus contributing to T-cell overactivation and B-cell overstimulation in SLE [29].

The transcription factor RFX1 plays central roles in the regulation of CD11a and CD70 expression in $\mathrm{CD}^{+} \mathrm{T}$ cells through the recruitment of DNMT1, HDAC1, and KMT1A (Suv39H1) [30,31]. Patients with SLE have decreased expression of RFX1, resulting in altered epigenetic regulation and consequent overexpression of $\mathrm{CD} 11 \mathrm{a}$ and $\mathrm{CD} 70$ in their $\mathrm{CD} 4^{+} \mathrm{T}$ cells and, in turn, leading to the development of autoreactivity and autoantibody overstimulation [30,31]. Taken together, these studies demonstrate that aberrant expression of the epigenetic machinery is associated with rheumatic disease and support the notion that the identified members of the epigenetic machinery which are overexpressed in rheumatic disease which can potentially be targeted could be suitable candidates for therapeutic intervention.

\section{Epigenetic 'marks' and histone variants as a target of autoreactivity in rheumatic disease}

An emerging body of evidence indicates that posttranslationally modified histones are primary targets for autoantibodies in patients with rheumatic disease. In SLE, apoptotic chromatin is present extracellularly and is suggested to be due to disturbed apoptosis or insufficient removal or both. This released chromatin can subsequently activate the immune system, resulting in the formation of autoantibodies. In a study of SLE, an autoantibody specific to histone $\mathrm{H} 3$ was identified, and subsequent analysis determined that this antibody preferentially reacted with trimethylated H3K27 (H3K27me3) in situ and was also able to specifically isolate chromatin containing H3K27me3 from plasma of patients with SLE [32]. Similar work from the same group has shown that additional autoantibodies in patients with SLE are specific to acetylation on histone $\mathrm{H} 4$ at lysines 8,12 , and 16 (H4K8,12,16Ac) and histone H2B (H2BK12Ac) [8].

Autoantibodies to modified histones are not restricted to SLE. In particular, anti-citrullinated protein antibodies have been identified as the most predictive factor for the development of RA, and several recent reports in the literature have identified autoantibodies directed against citrullinated histones as an early event in the progression of RA [2].
Interestingly, the enzyme associated with the citrullination of histones in RA has been identified as PAD4 [33], and autoantibodies directed against PAD4 have also been identified in patients with RA [34]. However, PAD4 itself has been found to be non-essential for disease formation in the $\mathrm{K} / \mathrm{BxN}$ murine autoantibody-mediated model of RA [35].

Neutrophil extracellular traps (NETs) normally function as a first line of defense against microbial organisms at the sites of infection by using a highly modified chromatin 'web' to direct a cellular suicide program distinct from apoptosis and necrosis. The fact that they are also present at regions containing immune system components and an inflammatory milieu has led to increasing evidence that NETs may trigger autoimmune responses. In a subsequent screen of sera comparing patients with SLE versus controls, it was found that the sera from patients with SLE reacted to acetylated histone $\mathrm{H} 2 \mathrm{~B}$ and were enriched for other histone PTMs associated with transcriptional repression [36]. Interestingly, it is well established that histones contained in NETs are frequently citrullinated [37,38] (reviewed in [39]).

CenP-A is a variant of histone H3, whose main functions involve the regulation of centromere identity and conferral of conformational rigidity to the centromere. CenP-A autoantibodies were recently detected in $34 \%$ of patients with scleroderma (systemic sclerosis) [40].

It is clear from the above that histone PTMs play an important role in the development of autoantibodies in patients with rheumatic disease. Also, the development of such autoantibodies occurs relatively early in the sequence of disease progression and makes targeting those enzymes responsible for such PTMs an attractive potential therapeutic intervention.

\section{miRNAs and epi-miRNAs in rheumatic disease}

miRNAs are specialized forms of ncRNA and consist of small, approximately 22-nucleotide single-stranded RNA molecules that regulate gene expression in cells by directly binding to and either degrading or translationally repressing targets. The RNA-induced silencing complex (RISC) is essential for miRNA-based silencing of gene expression, and members of RISC are known targets of autoantibodies associated with rheumatic disease [41]. Furthermore, a large body of evidence linking aberrant expression of miRNAs in rheumatic diseases, including SLE [42] and arthritis [9,41], has now emerged.

One of the most important aberrantly expressed miRNAs identified to date is miR-146a. This miRNA would appear to be a master regulator for several aspects of immunity, including the regulation of cytokines, such as tumor necrosis factor-alpha (TNF- $\alpha$ ), functioning in the negative feedback control of innate immunity in Tolllike receptor (TLR) signaling, and is involved with T-cell 
activation and is highly expressed in mature human memory $\mathrm{T}$ cells [41]. Furthermore, in a knockout mouse model of this miRNA, some loss of immunological tolerance was observed and resulted in fatal interferongamma (IFNY)-dependent immune-mediated lesions in different organs [41]. As miR-146a would appear to be a critical miRNA in autoimmune diseases, it is interesting to note that this miRNA was found to be lost in a mouse knockout model of the Mecp2 [43] and that the miR-146a promoter was highly methylated and Mecp2 was shown to bind to the miR-146a promoter [43]. Levels of this miRNA have also been shown to be either upregulated or downregulated in rheumatic disease. For instance, miR-146a has been found to be elevated in PBMCs, macrophages, $\mathrm{CD}^{+} \mathrm{T}$-cell subsets, and $\mathrm{CD} 79 \mathrm{a}^{+} \mathrm{B}$ cells of patients with RA [41,42]. Levels of miR-146a are decreased in patients with SLE [42] but are elevated in patients with Sjögren's syndrome [44]. One of the known targets of miR-146a is interleukin-1 receptor-associated kinase 1 (IRAK), resulting in attenuation of pro-inflammatory signaling. Interestingly, IRAK and Mecp2 localize to the same chromosomal location (Xq28), and variants of Mecp2 are associated with both increased risk of susceptibility and differential gene expression in patients with SLE [45], and IRAK1 has also been shown to be a significant risk factor for SLE [46]. The expression of miR-146a has also been shown to be affected by aging, particularly in macrophages, with an associated loss of responsiveness to lipopolysaccharide (LPS) stimulation. This loss of expression was found to be due to aberrant nuclear factor-kappa B (NF- $\mathrm{kB}$ ) binding to its promoter, and, critically, both DNMT inhibitors and HDAC inhibitors (HDACis) could reactivate expression of miR-146a and improve LPS-induced inflammatory responses in macrophages isolated from aged mice [47]. Other miRNAs overexpressed in autoimmune disease include miR-140 [48,49] and miR-155 [50].

Several miRNAs have been shown to directly target the epigenetic regulatory machinery and have collectively been termed 'epi-miRNAs'. In the following sections, I discuss the current evidence linking altered expression of these miRNAs with rheumatic disease.

miR-126 has been shown to target DNMT1 in SLE [51], whereas mIR-181-a has been shown to regulate KAT2B (PCAF) in SLE [28]. In this study, levels of this miRNA were shown to be downregulated in patients with SLE. Furthermore, loss of this miRNA was associated with elevated PCAF, impaired mouse double minute 2 homo$\log (\mathrm{Mdm} 2)$ ubiquitination, and induction of apoptosis [28].

Other epi-miRNAs associated with SLE include miR-21 and miR-148a, both of which have been shown to target and regulate DNMT1 in SLE CD4 ${ }^{+} \mathrm{T}$ cells [52]. In addition, significantly elevated expression of miR-21 has been demonstrated in the plasma of RA and SLE patients compared with controls [53].

Most recently, miR-29b levels were found to be upregulated in CD4 $4^{+}$cells of SLE patients compared with healthy donors [54]. This miRNA has previously been shown to affect DNMT1, and overexpression of miR-29b resulted in significant reduction of DNMT1 expression, which when overexpressed in $\mathrm{CD} 4^{+} \mathrm{T}$ cells from healthy donors led to the DNA hypomethylation and upregulation of genes encoding CD11a and CD70, whereas inhibition of miR-29b expression in $\mathrm{CD}_{4}^{+} \mathrm{T}$ cells from patients with lupus reversed these effects [54]. As loss of DNMT1 and hypomethylation is a common feature of SLE, the role of these miRNAs in SLE disease pathogenesis may involve the depletion of DNMT1, resulting in subsequent genomic hypomethylation, but further validation will be required.

As discussed earlier, HDAC4 has been suggested to play important roles, particularly in RA. In this regard, it is important to note that levels of HDAC4 have been shown to be downregulated by miR-29b, miR-140, and miR-365 in models of skeletogenesis and osteogenesis, further linking miRNA-mediated regulation of the epigenetic machinery in the rheumatic setting [55-57]. Other miRNAs have been shown to regulate different HDACs in osteoblasts. miR-200a has been shown to regulate the expression of SIRT-1, a class III HDAC [58], and interestingly this miRNA has also been shown to regulate the pre-osteoblast differentiation in part by regulation of distal-less homeobox 5 (Dlx5) [59]. As SIRT-1 activity has now been shown to be involved with osteogenic differentiation of mesenchymal stem cells [60], it will be important to determine whether this miRNA is affected in rheumatic disease. Indeed, levels of miR-200a have been shown to be decreased in SLE and inversely correlated with the SLE disease activity index (SLEDAI) [61], indicating that this miRNA may indeed play important roles in rheumatic disease by aberrantly affecting SIRT-1 activity. In this regard, levels of SIRT-1 have been shown to be elevated in a mouse model of SLE, and abrogation of this HDAC by siRNA was found to mitigate the damage of lupus in vivo in this model [62].

miRNAs therefore represent novel targets for the treatment of rheumatic disease. There are many programs/ companies that focus on developing miRNA-based therapeutics. Many of these involve technologies aimed at targeting these miRNAs, and the best known is the locked nucleic acid (LNA)-modified antisense oligonucleotide miravirsen, which targets the liver-expressed miRNA-122 and is currently in phase II clinical trials for the treatment of hepatitis C [63]. It is therefore conceivable that similar technologies could be used to target overexpressed miRNA species such as miR-2. 
Epigenetic targeting agents and rheumatic disease One of the first studies [64] linking the potential utility of epigenetic targeting agents in the treatment of rheumatic disease came from studies using the HDACis trichostatin A and suberonylanilide hydroxamic acid (vorinostat) on the MRL-lpr/lpr murine model of SLE [64-66]. Many other studies have now demonstrated the potential utility of HDACi in the treatment of autoimmune conditions, including rheumatic disease, particularly in the areas of dampening down pro-inflammatory cues [67] and through effects on the production and function of FOXP3 ${ }^{+}$regulatory $\mathrm{T}\left(\mathrm{T}_{\mathrm{reg}}\right)$ cells [68].

Although HDACs have received a significant amount of attention in this regard, it is well worth noting that other epigenetic regulatory machinery may also prove to be important potential therapeutic targets. For instance, a genome-wide study of histone $\mathrm{H} 3$ lysine 4 trimethylation by ChIP-chip in PBMCs of patients with SLE found significant alterations of $\mathrm{H} 3 \mathrm{~K} 4 \mathrm{me} 3$ which were associated with the pathogenesis of the disease. As such, it would appear that agents capable of targeting the relevant lysine methyltransferases or demethylases may become important new therapeutic targets for the treatment of rheumatic disease. In this regard, KDM5B is a specific H3K4me3/me2- lysine demethylase, and a novel inhibitor, 2,4-pyridine-dicarboxylic acid, targeting this enzyme has just been identified and isolated and thus may prove to have potential utility in the treatment of SLE or other rheumatic diseases or both [69].

As citrullinated histones would appear to be an important trigger in the development of autoantibodies early in the progression of RA, it may prove to be important to identify and develop agents that target the relevant enzyme responsible: PAD4. Most recently, ThrAsp-F-amidine (TDFA) was identified as a highly potent PAD4 inactivator with activity in vitro, raising the possibility that this may have therapeutic potential in the treatment of RA [70]. Another series of PAD4 inhibitors (lead compound YW3-56), whose activity alters the expression of genes controlling the cell cycle and cell death but also induces cellular autophagy, has been developed [71]. As a caveat, it has recently been suggested that autophagy is activated in RA, particularly during joint destruction, and that autophagy inhibitors may be effective in treating RA joint destruction [72]. As such, PAD4 inhibitors may exacerbate existing RA. Further studies will be required to determine whether PAD4 inhibitors have therapeutic potential in the treatment of autoimmune conditions.

The expression of many miRNAs has been shown to be regulated via epigenetic mechanisms [73,74], and this may have important implications for the treatment of rheumatic disease. For example, both DNMT inhibitors and HDACis have been shown to restore miR-146a expression in the macrophages of aged mice [47]. This indicates a further potential for epigenetic targeting agents to alter the expression of a critical master regulator of immunity.

It is increasingly clear that epigenetics plays important roles in the regulation of pro-inflammatory cues in rheumatic disease. A plethora of studies have identified dysregulated pro-inflammatory cytokine expression in models of rheumatic disease; furthermore, there is strong evidence that epigenetic targeting agents such as HDACi may play important roles in regulating cellular responses to such cues [75]. We and others have shown that epigenetic targeting agents can affect the expression of various pro-inflammatory cytokines [76]. However, it must be noted that HDACi can induce the expression of pro-inflammatory cytokines such as CXCL-8 [76] and IL-20 [77], both of which have been shown to be important in pro-inflammatory diseases such as rheumatic disease [78]. IL-17 is one such pro-inflammatory cytokine which is a key element associated with autoimmune diseases, including SLE. Six isoforms of this cytokine have been identified (IL17A-F), and a recent study on IL-17A demonstrated strong epigenetic differences in its regulation in patients with SLE [79]. In particular, decreased H3K27 methylation in activated naïve $\mathrm{CD}_{4}^{+}$ $\mathrm{T}$ cells and in $\mathrm{T}$ cells from patients with SLE was associated with decreased DNA methylation at the IL-17A promoter, together with reduced recruitment of HDAC1 and DNMT3a. These findings raise the issue that HDACi may have potentially 'good' and 'bad' effects within the autoimmune disease setting, particularly with regard to pro-inflammatory cytokines. However, we and others have also shown that epigenetic targeting agents have the ability to affect the stability of both expressed mRNAs and proteins [80], and this effect has also been observed in RA, in which HDACi significantly reduced the stability of IL-6 mRNA in FLSs and macrophages [81].

It is clear from the previous sections that epigenetic targeting agents have the potential to alter or restore expression of critical factors in rheumatic disease or may have the ability to ablate or ameliorate the pro-inflammatory environments caused by these diseases. Nevertheless, exciting data have emerged from a phase II clinical trial of givinostat (ITF2357), an orally bioavailable HDACi, in patients with JIA (ClinicalTrials.gov NCT00570661). In this trial, 17 patients were given givinostat at a dose of $1.5 \mathrm{mg} / \mathrm{kg}$ per day for up to 12 weeks. At the end of the trial, a significant therapeutic benefit was observed in the patients, particularly in the areas of mobility and well-being. This was coupled with a decrease in the number of joints with active arthritis, as assessed by the number of painful and swollen joints. Critically, the safety and tolerability profile of the drug 
was extremely good; the majority of adverse events were reported as mild or moderate and consisted of nausea, vomiting, and fatigue [82]. A second clinical trial (ClinicalTrials.gov NCT01557452) involving an openlabel extension of a dose-finding study in polyarticular JIA is ongoing, and a primary outcome to determine long-term safety is running.

\section{The potential utility of dietary epigenetic targeting agents for rheumatic disease}

A significant issue concerning the use of epigenetic targeting agents in conditions such as rheumatic disease is that these are chronic conditions and require longterm treatment regimens. Nutrition-based interventions, therefore, may provide a novel therapeutic avenue of approach with this factor in mind. A large number of naturally occurring bioactive compounds have been shown to inhibit various members of the epigenetic machinery [83]. Evidence to link these naturally occurring compounds with potential patient benefit in rheumatic disease is now emerging.

One of the most extensively studied of these compounds is curcumin, a natural polyphenol occurring in turmeric. Conversely, this compound has been shown to inhibit both HDACs and KATs (reviewed in [84]). Two pilot studies have been conducted in patients with rheumatic disease. In the first study, the safety and effectiveness of curcumin alone and in combination with diclofenac sodium were evaluated in patients with active RA [85]. Forty-five patients with RA were randomly assigned to one of three groups with patients receiving curcumin (500 mg) and diclofenac sodium $(50 \mathrm{mg}$ ) alone or in combination. The primary endpoint in this study was a reduction in Disease Activity Score (DAS), and secondary endpoints involved the assessment of American College of Rheumatology (ACR) criteria for reductions in tenderness and joint swelling scores. Patients received treatment for an 8-week period. Overall, all groups showed significant improvement in all tested ACR components and in their DASs. Critically, the patients who received curcumin showed the best improvements and were significantly better than the patients who received diclofenac sodium. Most importantly, curcumin treatment was found to be safe and was not related to any adverse events [85]. A second study examined the effect of Meriva (Thorne Research, Inc., Dover, ID, USA), a formulation of curcumin complexed with phosphatidylcholine, on joint pain and improvement in joint function of patients with OA [86]. In this study, 100 patients received treatment with this compound for a period of 8 months. Clinical endpoints were WOMAC (Western Ontario and McMaster Universities Arthritis Index) score, Karnofsky Performance Scale Index, and treadmill walking performance. At the end of the study,
Meriva was shown to significantly improve all clinical endpoints. Secondary endpoints examined were a panel of inflammatory markers. Meriva was found to significantly decrease the expression of IL-6, IL-1 $\beta$, sCD40L, and sVCAM-1 (soluble form of vascular cell adhesion molecule-1) in patients, whereas the control arm had no significant alterations in the levels of these pro-inflammatory markers [86]. These results indicate that curcumin may have important potential in the treatment of rheumatic disease. It must be noted that, in pancreatic cancer cells in vitro, a curcumin analog has also been shown to induce the expression of mIR-146a. As previously discussed, this miRNA may be a critical component in rheumatic disease, and it will be important to determine whether curcumin or curcumin-based analogs can affect this miRNA within the rheumatic disease setting.

Another novel bioactive dietary compound present in many pigmented fruits and vegetables is delphinidin (reviewed in [87]), which has been shown to be a specific inhibitor of K-acetyltransferases KAT3A/KAT3B [88]. Critically, delphinidin has also been shown to suppress inflammatory signaling via prevention of NF- $\mathrm{kB}$ acetylation in a human RA FLS cell line [88]. Similar effects on NF- $\mathrm{kB}$ have been seen for this compound in prostate cells both in vitro and in vivo [89], indicating that this bioactive compound may also have potential utility in the treatment of rheumatic disease or other autoimmune conditions, particularly those that are associated with NF-kB-mediated inflammation.

Resveratrol is another natural compound that has been extensively studied for its potential utility in the management of diabetes. This compound is thought to be an activator of SIRT-1, but this view has since been called into question [90]. It has since been determined to function by inhibiting cAMP phosphodiesterases [91], and, as a consequence, levels of $\mathrm{NAD}^{+}$increase with concomitant increased SIRT-1 activity. Nevertheless, a large body of evidence demonstrates the potential efficacy of this compound in modulating pro-inflammatory effects in arthritis, suggesting that further studies will be required to determine the true nature of this compound.

Sulforaphane (SFN) is a naturally occurring organosulfur compound that has been shown to inhibit HDACs (reviewed in $[84,92]$ ). According to the ClinicalTrials.gov website [93], several clinical trials (for example, NCT01543074 and NCT01265953) are currently recruiting or will be recruiting in the near future to examine the effects of SFN in patients, but so far there have been no clinical trials on the potential of this compound in autoimmune disease. Of particular interest, NCT01357070 is currently recruiting patients to examine the effect of broccoli sprout on the blood levels of SFN to reduce responsiveness of patient immune systems. Specifically, 
the trial will examine, as a primary outcome, the resistance of leukocytes to inflammatory activation following an experimental stress following the consumption of a 'broccoli smoothie' containing SFN to determine whether it can protect white blood cells from becoming activated in the presence of an experimental stress and how long this protective effect lasts. Nevertheless, SFN has been shown to have effects on the immune system. It has been shown to inhibit the Th2 immune response in ovalbumininduced asthma [94]. The potential utility of this compound in the treatment of rheumatoid disease was demonstrated recently in an experimental mouse model of arthritis [95]. In vitro studies first demonstrated that RA FLSs treated with SFN resulted in the induction of apoptosis by reducing the levels of the anti-apoptotic protein Bcl-2 while inducing levels of pro-apoptotic p53 and Bax and decreasing levels of a pAkt [95]. In contrast, activated $\mathrm{T}$ cells, which are well established as contributing to joint destruction in RA, were insensitive to SFNinduced apoptosis [95]. Most importantly, SFN treatment of activated T cells was associated with a suppression of both cell proliferation and the expression of pro-inflammatory cytokines in these activated $\mathrm{T}$ cells [95]. The authors subsequently examined the effects of SFN on collagen-induced arthritis (CIA) in mice. Using intraperitoneal injection of SFN, the authors demonstrated that this compound ameliorated the effects of CIA with lower degrees of inflammation, synovial hyperplasia, pannus formation, and bone destruction compared with vehicle alone [95]. This was accompanied by reduced Tcell proliferative responses and lowered secretion of proinflammatory cytokines such as IL-17, TNF $\alpha$, IL-6, and IFNY [95]. To validate these observations, the authors reexamined the effects of SFN in a passive model of RA (RA induced by injections of anti-CII antibody). Again, the severity of the RA was reduced significantly by SFN, and the peak arthritis severity scores were $10.3 \pm 2.8$ (mean \pm standard deviation) in vehicle-treated mice versus $5.5 \pm 2.1$ in SFN-treated mice [95]. Although effectiveness was demonstrated, it must be noted that there were no apparent adverse effects following administration of SFN, including changes in weight, physical appearance, or behavior [95], thus indicating that SFN may have significant potential for the treatment of patients with RA. However, it must be noted that, in this paper, the authors did not determine whether the effects of SFN were a result of its HDACi activity versus its other known activities such as its ability to induce phase II antioxidant and detoxification enzymes [96].

\section{Conclusions}

It is clear that aberrant epigenetic regulatory mechanisms play important roles in the development and pathogenesis of rheumatic disease. A large body of evidence also indicates that targeting the epigenetic regulatory machinery may have potential therapeutic benefit in the treatment of such conditions. Further work will be required to clarify and expand on these possibilities.

This article is part of the series on Epigenetics and rheumatic diseases, edited by Nan Shen. Other articles in this series can be found at http://arthritis-research.com/series/epigenetics

\section{Abbreviations}

ACR, American College of Rheumatology; ChIP, chromatin

immunoprecipitation; CIA, collagen-induced arthritis; DAS, Disease Activity Score; DM, differentially methylated; DNMT, DNA methyltransferase; FLS, fibroblast-like synoviocyte; HDAC, histone deacetylase; HDACi, histone deacetylase inhibitor; IFNy, interferon-gamma; IL, interleukin; IRAK, interleukin-1 receptor-associated kinase 1; JIA, juvenile idiopathic arthritis; KAT, K-acetyltransferase; KDM, K-demethylase; KMT, K-methyltransferase; LPS, lipopolysaccharide; MBD, methyl-CpG-binding domain protein; Mecp2, methyl CpG-binding protein 2; miRNA, microRNA; MMP, matrix metalloproteinase; ncRNA, non-coding RNA; NET, neutrophil extracellular trap; NF-KB, nuclear factor-kappa B; OA, osteoarthritis; PBMC, peripheral blood mononuclear cell; PTM, post-translational modification; RA, rheumatoid arthritis; RISC, RNAinduced silencing complex; SFN, sulforaphane; siRNA, small interfering RNA: SLE, systemic lupus erythematosus; TNF-a, tumor necrosis factor-alpha.

\section{Competing interests}

The author declares that he has no competing interests.

\section{Acknowledgments}

The author wishes to acknowledge the many contributions of those researchers whose work he was unable to cite owing to space constraints.

\section{Published: 14 March 2013}

\section{References}

1. American College of Rheumatology homepage [www.rheumatology.org].

2. Sokolove J, Bromberg R, Deane KD, Lahey LJ, Derber LA, Chandra PE, Edison JD, Gilliland WR, Tibshirani RJ, Norris JM, Holers VM, Robinson WH: Autoantibody epitope spreading in the pre-clinical phase predicts progression to rheumatoid arthritis. PLoS One 2012, 7:e35296.

3. Sandoval J, Esteller M: Cancer epigenomics: beyond genomics. Curr Opin Genet Dev 2012, 22:50-55.

4. Gray SG, De Meyts P: Role of histone and transcription factor acetylation in diabetes pathogenesis. Diabetes Metab Res Rev 2005, 21:416-433.

5. Gray SG: Epigenetic treatment of neurological disease. Epigenomics 2011, 3:431-450.

6. Feinberg AP, Vogelstein B: Hypomethylation distinguishes genes of some human cancers from their normal counterparts. Nature 1983, 301:89-92.

7. Ballestar E: Epigenetic alterations in autoimmune rheumatic diseases. Nat Rev Rheumatol 2011, 7:263-271.

8. Zouali M: Epigenetics in lupus. Ann N Y Acad Sci 2011, 1217:154-165.

9. Goldring MB, Marcu KB: Epigenomic and microRNA-mediated regulation in cartilage development, homeostasis, and osteoarthritis. Trends Mol Med 2012, 18:109-118.

10. Javierre BM, Fernandez AF, Richter J, Al-Shahrour F, Martin-Subero Jl, Rodriguez-Ubreva J, Berdasco M, Fraga MF, O'Hanlon TP, Rider LG, Jacinto FV, Lopez-Longo FJ, Dopazo J, Forn M, Peinado MA, Carreño L, Sawalha AH, Harley JB, Siebert R, Esteller M, Miller FW, Ballestar E: Changes in the pattern of DNA methylation associate with twin discordance in systemic lupus erythematosus. Genome Res 2010, 20:170-179.

11. Jeffries MA, Dozmorov M, Tang Y, Merrill JT, Wren JD, Sawalha AH: Genomewide DNA methylation patterns in CD4+ T cells from patients with systemic lupus erythematosus. Epigenetics 2011, 6:593-601.

12. Zhu X, Liang J, Li F, Yang Y, Xiang L, Xu J: Analysis of associations between the patterns of global DNA hypomethylation and expression of DNA methyltransferase in patients with systemic lupus erythematosus. Int $\mathrm{J}$ Dermatol 2011, 50:697-704.

13. Lei W, Luo Y, Lei W, Luo Y, Yan K, Zhao S, Li Y, Qiu X, Zhou Y, Long H, Zhao M, Liang Y, Su Y, Lu Q: Abnormal DNA methylation in CD4+ T cells from 
patients with systemic lupus erythematosus, systemic sclerosis, and dermatomyositis. Scand J Rheumatol 2009, 38:369-374.

14. Nakano K, Whitaker JW, Boyle DL, Wang W, Firestein GS: DNA methylome signature in rheumatoid arthritis. Ann Rheum Dis 2013, 72:110-117.

15. Nakano K, Boyle DL, Firestein GS: Regulation of DNA Methylation in Rheumatoid Arthritis Synoviocytes. J Immuno/ 2013, 190:1297-1303.

16. Ellis JA, Munro JE, Chavez RA, Gordon L, Joo JE, Akikusa JD, Allen RC, Ponsonby AL, Craig JM, Saffery R: Genome-scale case-control analysis of CD4+ T-cell DNA methylation in juvenile idiopathic arthritis reveals potential targets involved in disease. Clin Epigenetics 2012, 4:20.

17. Bui C, Barter MJ, Scott UL, XuY, Galler M, Reynard LN, Rowan AD, Young DA CAMP response element-binding (CREB) recruitment following a specific $\mathrm{CpG}$ demethylation leads to the elevated expression of the matrix metalloproteinase 13 in human articular chondrocytes and osteoarthritis. FASEB J 2012, 26:3000-3011.

18. Minguez P, Letunic I, Parca L, Bork P: PTMcode: a database of known and predicted functional associations between post-translational modifications in proteins. Nucleic Acids Res 2013, 41:D306-311.

19. Minguez P, Parca L, Diella F, Mende DR, Kumar R, Helmer-Citterich M, Gavin $A C$, van Noort $V$, Bork P: Deciphering a global network of functionally associated post-translational modifications. Mol Syst Biol 2012, 8:599.

20. Horiuchi M, Morinobu A, Chin T, Sakai Y, Kurosaka M, Kumagai S: Expression and function of histone deacetylases in rheumatoid arthritis synovial fibroblasts. J Rheumatol 2009, 36:1580-1589.

21. Gillespie J, Savic S, Wong C, Hempshall A, Inman M, Emery P, Grigg R, McDermott MF: Histone deacetylases are dysregulated in rheumatoid arthritis and a novel histone deacetylase 3-selective inhibitor reduces interleukin-6 production by peripheral blood mononuclear cells from rheumatoid arthritis patients. Arthritis Rheum 2012, 64:418-422.

22. Huber LC, Brock M, Hemmatazad H, Giger OT, Moritz F, Trenkmann M, Distler JH, Gay RE, Kolling C, Moch H, Michel BA, Gay S, Distler O, Jüngel A: Histone deacetylase/acetylase activity in total synovial tissue derived from rheumatoid arthritis and osteoarthritis patients. Arthritis Rheum 2007 56:1087-1093.

23. Maciejewska-Rodrigues $H$, Karouzakis E, Strietholt $S$, Hemmatazad H, Neidhart M, Ospelt C, Gay RE, Michel BA, Pap T, Gay S, Jungel A: Epigenetics and rheumatoid arthritis: the role of SENP1 in the regulation of MMP-1 expression. J Autoimmun 2010, 35:15-22

24. Yan K, Cao Q, Reilly CM, Young NL, Garcia BA, Mishra N: Histone deacetylase 9 deficiency protects against effector T cell-mediated systemic autoimmunity. J Biol Chem 2011, 286:28833-28843.

25. Trenkmann M, Brock M, Gay RE, Kolling C, Speich R, Michel BA, Gay S, Huber $L C$ : Expression and function of EZH2 in synovial fibroblasts: epigenetic repression of the Wnt inhibitor SFRP1 in rheumatoid arthritis. Ann Rheum Dis 2011, 70:1482-1488

26. Levy D, Kuo AJ, Chang Y, Schaefer U, Kitson C, Cheung P, Espejo A, Zee BM, Liu CL, Tangsombatvisit S, Tennen RI, Kuo AY, Tanjing S, Cheung R, Chua KF, Utz PJ, Shi X, Prinjha RK, Lee K, Garcia BA, Bedford MT, Tarakhovsky A, Cheng X, Gozani O: Lysine methylation of the NF-kappaB subunit RelA by SETD6 couples activity of the histone methyltransferase GLP at chromatin to tonic repression of NF-kappaB signaling. Nat Immunol 2011, 12:29-36.

27. Hu N, Qiu X, Luo Y, Yuan J, Li Y, Lei W, Zhang G, Zhou Y, Su Y, Lu Q: Abnormal histone modification patterns in lupus CD4+T cells. J Rheumatol 2008, 35:804-810.

28. Lashine YA, Seoudi AM, Salah S, Abdelaziz Al: Expression signature of microRNA-181-a reveals its crucial role in the pathogenesis of paediatric systemic lupus erythematosus. Clin Exp Rheumatol 2011, 29:351-357.

29. Zhang Q, Long H, Liao J, Zhao M, Liang G, Wu X, Zhang P, Ding S, Luo S, Lu Q: Inhibited expression of hematopoietic progenitor kinase 1 associated with loss of jumonji domain containing 3 promoter binding contributes to autoimmunity in systemic lupus erythematosus. J Autoimmun 2011 37:180-189.

30. Zhao M, Sun Y, Gao F, Wu X, Tang J, Yin H, Luo Y, Richardson B, Lu Q: Epigenetics and SLE: RFX1 downregulation causes CD11a and CD70 overexpression by altering epigenetic modifications in lupus CD4+ T cells. J Autoimmun 2010, 35:58-69.

31. Zhao M, Wu X, Zhang Q, Luo S, Liang G, Su Y, Tan Y, Lu Q: RFX1 regulates CD70 and CD11a expression in lupus $T$ cells by recruiting the histone methyltransferase SUV39H1. Arthritis Res Ther 2010, 12:R227.

32. van Bavel CC, Dieker JW, Kroeze Y, Tamboer WP, Voll R, Muller S, Berden JH, van der Vlag J: Apoptosis-induced histone $\mathrm{H} 3$ methylation is targeted by autoantibodies in systemic lupus erythematosus. Ann Rheum Dis 2011, 70:201-207.

33. Darrah E, Rosen A, Giles JT, Andrade F: Peptidylarginine deiminase 2, 3 and 4 have distinct specificities against cellular substrates: novel insights into autoantigen selection in rheumatoid arthritis. Ann Rheum Dis 2012, 71:92-98.

34. Auger I, Charpin C, Balandraud N, Martin M, Roudier J: Autoantibodies to PAD4 and BRAF in rheumatoid arthritis. Autoimmun Rev 2012, 11:801-803.

35. Rohrbach AS, Hemmers S, Arandjelovic S, Corr M, Mowen KA: PAD4 is not essential for disease in the $\mathrm{K} / \mathrm{BxN}$ murine autoantibody-mediated model of arthritis. Arthritis Res Ther 2012, 14:R104.

36. Liu CL, Tangsombatvisit S, Rosenberg JM, Mandelbaum G, Gillespie EC, Gozani OP, Alizadeh AA, Utz PJ: Specific post-translational histone modifications of neutrophil extracellular traps as immunogens and potential targets of lupus autoantibodies. Arthritis Res Ther 2012, 14:R25.

37. Wang Y, Li M, Stadler S, Correll S, Li P, Wang D, Hayama R, Leonelli L, Han H, Grigoryev SA, Allis CD, Coonrod SA: Histone hypercitrullination mediates chromatin decondensation and neutrophil extracellular trap formation. J Cell Biol 2009, 184:205-213.

38. Leshner M, Wang S, Lewis C, Zheng H, Chen XA, Santy L, Wang Y: PAD4 mediated histone hypercitrullination induces heterochromatin decondensation and chromatin unfolding to form neutrophil extracellular trap-like structures. Front Immuno/ 2012, 3:307.

39. Rohrbach AS, Slade DJ, Thompson PR, Mowen KA: Activation of PAD4 in NET formation. Front Immunol 2012, 3:360.

40. Hudson M, Mahler M, Pope J, You D, Tatibouet S, Steele R, Baron M, Fritzler M: Clinical correlates of CENP-A and CENP-B antibodies in a large cohort of patients with systemic sclerosis. J Rheumatol 2012, 39:787-794.

41. Ceribelli A, Yao B, Dominguez-Gutierrez PR, Nahid MA, Satoh M, Chan EK MicroRNAs in systemic rheumatic diseases. Arthritis Res Ther 2011, 13:229.

42. Dai $R$, Ahmed SA: MicroRNA, a new paradigm for understanding immunoregulation, inflammation, and autoimmune diseases. Trans/ Res 2011, 157:163-179

43. Urdinguio RG, Fernandez AF, Lopez-Nieva P, Rossi S, Huertas D, Kulis M, Liu CG, Croce CM, Calin GA, Esteller M: Disrupted microRNA expression caused by Mecp2 loss in a mouse model of Rett syndrome. Epigenetics 2010, 5:656-663.

44. Pauley KM, Stewart CM, Gauna AE, Dupre LC, Kuklani R, Chan AL, Pauley BA, Reeves WH, Chan EK, Cha S: Altered miR-146a expression in Sjogren's syndrome and its functional role in innate immunity. Eur J Immunol 2011, 41:2029-2039.

45. Webb R, Wren JD, Jeffries M, Kelly JA, Kaufman KM, Tang Y, Frank MB, Merrill J, Kimberly RP, Edberg JC, Ramsey-Goldman R, Petri M, Reveille JD, Alarcón GS, Vilá LM, Alarcón-Riquelme ME, James JA, Vyse TJ, Moser KL, Gaffney PM, Gilkeson GS, Harley JB, Sawalha AH: Variants within MECP2, a key transcription regulator, are associated with increased susceptibility to lupus and differential gene expression in patients with systemic lupus erythematosus. Arthritis Rheum 2009, 60:1076-1084.

46. Jacob CO, Zhu J, Armstrong DL, Yan M, Han J, Zhou XJ, Thomas JA, Reiff A, Myones BL, Ojwang JO, Kaufman KM, Klein-Gitelman M, McCurdy D, WagnerWeiner L, Silverman E, Ziegler J, Kelly JA, Merrill JT, Harley JB, RamseyGoldman R, Vila LM, Bae SC, Vyse TJ, Gilkeson GS, Gaffney PM, Moser KL, Langefeld CD, Zidovetzki R, Mohan C: Identification of IRAK1 as a risk gene with critical role in the pathogenesis of systemic lupus erythematosus. Proc Natl Acad Sci U S A 2009, 106:6256-6261.

47. Jiang M, Xiang Y, Wang D, Gao J, Liu D, Liu Y, Liu S, Zheng D: Dysregulated expression of miR-146a contributes to age-related dysfunction of macrophages. Aging Cell 2012, 11:29-40.

48. Miyaki S, Nakasa T, Otsuki S, Grogan SP, Higashiyama R, Inoue A, Kato Y, Sato T, Lotz MK, Asahara H: MicroRNA-140 is expressed in differentiated human articular chondrocytes and modulates interleukin-1 responses. Arthritis Rheum 2009, 60:2723-2730.

49. Miyaki S, Sato T, Inoue A, Otsuki S, Ito Y, Yokoyama S, Kato Y, Takemoto F, Nakasa T, Yamashita S, Takada S, Lotz MK, Ueno-Kudo H, Asahara H: MicroRNA-140 plays dual roles in both cartilage development and homeostasis. Genes Dev 2010, 24:1173-1185.

50. Divekar AA, Dubey S, Gangalum PR, Singh RR: Dicer insufficiency and microRNA-155 overexpression in lupus regulatory T cells: an apparent paradox in the setting of an inflammatory milieu. J Immunol 2011, 186:924-930.

51. Zhao S, Wang Y, Liang Y, Zhao M, Long H, Ding S, Yin H, Lu Q: MicroRNA-126 
regulates DNA methylation in CD4+T cells and contributes to systemic lupus erythematosus by targeting DNA methyltransferase 1. Arthritis Rheum 2011, 63:1376-1386.

52. Pan W, Zhu S, Yuan M, Cui H, Wang L, Luo X, Li J, Zhou H, Tang Y, Shen N: MicroRNA-21 and microRNA-148a contribute to DNA hypomethylation in lupus CD4+ T cells by directly and indirectly targeting DNA methyltransferase 1. J Immunol 2010, 184:6773-6781

53. Wang H, Peng W, Ouyang X, Li W, Dai Y: Circulating microRNAs as candidate biomarkers in patients with systemic lupus erythematosus. Trans/ Res 2012, 160:198-206.

54. Qin H, Zhu X, Liang J, Wu J, Yang Y, Wang S, Shi W, Xu J: MicroRNA-29b contributes to DNA hypomethylation of CD4+ T cells in systemic lupus erythematosus by indirectly targeting DNA methyltransferase 1 . J Dermatol Sci 2013, 69:61-67.

55. Guan YJ, Yang X, Wei L, Chen Q: MiR-365: a mechanosensitive microRNA stimulates chondrocyte differentiation through targeting histone deacetylase 4. FASEB J 2011, 25:4457-4466.

56. Tuddenham L, Wheeler G, Ntounia-Fousara S, Waters J, Hajihosseini MK, Clark I, Dalmay T: The cartilage specific microRNA-140 targets histone deacetylase 4 in mouse cells. FEBS Lett 2006, 580:4214-4217.

57. Li Z, Hassan MQ, Jafferji M, Aqeilan RI, Garzon R, Croce CM, van Wijnen AJ, Stein JL, Stein GS, Lian JB: Biological functions of miR-29b contribute to positive regulation of osteoblast differentiation. J Biol Chem 2009, 284:15676-15684

58. Eades $G$, Yao Y, Yang M, Zhang Y, Chumsri S, Zhou Q: miR-200a regulates SIRT1 expression and epithelial to mesenchymal transition (EMT)-like transformation in mammary epithelial cells. J Bio/ Chem 2011, 286:25992-26002

59. Itoh T, Nozawa Y, Akao Y: MicroRNA-141 and -200a are involved in bone morphogenetic protein-2-induced mouse pre-osteoblast differentiation by targeting distal-less homeobox 5. J Biol Chem 2009, 284:19272-19279.

60. Shakibaei M, Shayan P, Busch F, Aldinger C, Buhrmann C, Lueders C, Mobasheri A: Resveratrol mediated modulation of Sirt-1/Runx2 promotes osteogenic differentiation of mesenchymal stem cells: potential role of Runx2 deacetylation. PLoS One 2012, 7:e35712.

61. Wang G, Tam LS, Li EK, Kwan BC, Chow KM, Luk CC, Li PK, Szeto CC: Serum and urinary free microRNA level in patients with systemic lupus erythematosus. Lupus 2011, 20:493-500.

62. Hu N, Long H, Zhao M, Yin H, Lu Q: Aberrant expression pattern of histone acetylation modifiers and mitigation of lupus by SIRT1-siRNA in MRL/lpr mice. Scand J Rheumatol 2009, 38:464-471.

63. Lindow M, Kauppinen S: Discovering the first microRNA-targeted drug. J Cell Biol 2012, 199:407-412.

64. Mishra N, Reilly CM, Brown DR, Ruiz P, Gilkeson GS: Histone deacetylase inhibitors modulate renal disease in the MRL-Ipr/Ipr mouse. J Clin Invest 2003, 111:539-552.

65. Reilly CM, Mishra N, Miller JM, Joshi D, Ruiz P, Richon VM, Marks PA, Gilkeson GS: Modulation of renal disease in MRL/lpr mice by suberoylanilide hydroxamic acid. J Immunol 2004, 173:4171-4178.

66. Garcia BA, Busby SA, Shabanowitz J, Hunt DF, Mishra N: Resetting the epigenetic histone code in the MRL-Ipr/lpr mouse model of lupus by histone deacetylase inhibition. J Proteome Res 2005, 4:2032-2042.

67. Grabiec AM, Tak PP, Reedquist KA: Function of histone deacetylase inhibitors in inflammation. Crit Rev Immuno/ 2011, 31:233-263.

68. Saouaf SJ, Li B, Zhang G, Shen Y, Furuuchi N, Hancock WW, Greene MI: Deacetylase inhibition increases regulatory $T$ cell function and decreases incidence and severity of collagen-induced arthritis. Exp Mol Pathol 2009, 87:99-104.

69. Kristensen LH, Nielsen AL, Helgstrand C, Lees M, Cloos P, Kastrup JS, Helin K, Olsen L, Gajhede M: Studies of H3K4me3 demethylation by KDM5B/ Jarid1B/PLU1 reveals strong substrate recognition in vitro and identifies 2,4-pyridine-dicarboxylic acid as an in vitro and in cell inhibitor. FEBS J 2012, 279:1905-1914.

70. Jones JE, Slack JL, Fang P, Zhang X, Subramanian V, Causey CP, Coonrod SA, Guo M, Thompson PR: Synthesis and screening of a haloacetamidine containing library to identify PAD4 selective inhibitors. ACS Chem Biol 2012, 7:160-165.

71. Wang Y, Li P, Wang S, Hu J, Chen XA, Wu J, Fisher M, Oshaben K, Zhao N, Gu Y, Wang D, Chen G, Wang Y: Anticancer peptidylarginine deiminase (PAD) inhibitors regulate the autophagy flux and the mammalian target of rapamycin complex 1 activity. J Biol Chem 2012, 287:25941-25953.
72. Lin NY, Beyer C, GießI A, Kireva T, Scholtysek C, Uderhardt S, Munoz LE, Dees C, Distler A, Wirtz S, Krönke G, Spencer B, Distler O, Schett G, Distler JH: Autophagy regulates TNFalpha-mediated joint destruction in experimental arthritis. Ann Rheum Dis 2012 Sep 12. [Epub ahead of print].

73. Baer C, Claus R, Plass C: Genome-wide epigenetic regulation of miRNAs in cancer. Cancer Res 2013, 73:473-477.

74. Lopez-Serra P, Esteller M: DNA methylation-associated silencing of tumorsuppressor microRNAs in cancer. Oncogene 2012, 31:1609-1622.

75. Hedrich CM, Tsokos GC: Epigenetic mechanisms in systemic lupus erythematosus and other autoimmune diseases. Trends Mol Med 2011 , 17:714-724.

76. Baird AM, Gray SG, O'Byrne KJ: Epigenetics underpinning the regulation of the CXC (ELR+) chemokines in non-small cell lung cancer. PLoS One 2011, 6:e14593.

77. Baird AM, Gray SG, O'Byrne KJ: IL-20 is epigenetically regulated in NSCLC and down regulates the expression of VEGF. Eur J Cancer 2011, 47:1908-1918.

78. Hofmann SR, Rosen-Wolff A, Tsokos GC, Hedrich CM: Biological properties and regulation of IL-10 related cytokines and their contribution to autoimmune disease and tissue injury. Clin Immunol 2012, 143:116-127.

79. Rauen T, Hedrich CM, Juang YT, Tenbrock K, Tsokos GC: CAMP-responsive element modulator (CREM)alpha protein induces interleukin 17A expression and mediates epigenetic alterations at the interleukin-17A gene locus in patients with systemic lupus erythematosus. J Biol Chem 2011, 286:43437-43446

80. Cathcart MC, Gray SG, Baird AM, Boyle E, Gately K, Kay E, Cummins R, Pidgeon GP, O'Byrne KJ: Prostacyclin synthase expression and epigenetic regulation in nonsmall cell lung cancer. Cancer 2011, 117:5121-5132.

81. Grabiec AM, Korchynskyi O, Tak PP, Reedquist KA: Histone deacetylase inhibitors suppress rheumatoid arthritis fibroblast-like synoviocyte and macrophage IL-6 production by accelerating mRNA decay. Ann Rheum Dis 2012, 71:424-431.

82. Vojinovic J, Damjanov N, D'Urzo C, Furlan A, Susic G, Pasic S, lagaru N, Stefan M, Dinarello CA: Safety and efficacy of an oral histone deacetylase inhibitor in systemic-onset juvenile idiopathic arthritis. Arthritis Rheum 2011, 63:1452-1458

83. Link A, Balaguer F, Goel A: Cancer chemoprevention by dietary polyphenols: promising role for epigenetics. Biochem Pharmacol 2010, 80:1771-1792.

84. Lawless MW, O'Byrne KJ, Gray SG: Oxidative stress induced lung cancer and COPD: opportunities for epigenetic therapy. J Cell Mol Med 2009, 13:2800-2821.

85. Chandran B, Goel A: A randomized, pilot study to assess the efficacy and safety of curcumin in patients with active rheumatoid arthritis. Phytother Res 2012, 26:1719-1725.

86. Belcaro G, Cesarone MR, Dugall M, Pellegrini L, Ledda A, Grossi MG, Togni S, Appendino G: Efficacy and safety of Meriva(R), a curcuminphosphatidylcholine complex, during extended administration in osteoarthritis patients. Altern Med Rev 2010, 15:337-344

87. Thomasset S, Teller N, Cai H, Marko D, Berry DP, Steward WP, Gescher AJ: Do anthocyanins and anthocyanidins, cancer chemopreventive pigments in the diet, merit development as potential drugs? Cancer Chemother Pharmacol 2009, 64:201-211.

88. Seong AR, Yoo JY, Choi K, Lee MH, Lee YH, Lee J, Jun W, Kim S, Yoon HG: Delphinidin, a specific inhibitor of histone acetyltransferase, suppresses inflammatory signaling via prevention of NF-kappaB acetylation in fibroblast-like synoviocyte MH7A cells. Biochem Biophys Res Commun 2011, 410:581-586

89. Hafeez BB, Siddiqui IA, Asim M, Malik A, Afaq F, Adhami VM, Saleem M, Din M, Mukhtar H: A dietary anthocyanidin delphinidin induces apoptosis of human prostate cancer PC3 cells in vitro and in vivo: involvement of nuclear factor-kappaB signaling. Cancer Res 2008, 68:8564-8572.

90. Beher D, Wu J, Cumine S, Kim KW, Lu SC, Atangan L, Wang M: Resveratrol is not a direct activator of SIRT1 enzyme activity. Chem Biol Drug Des 2009, 74:619-624.

91. Park SJ, Ahmad F, Philp A, Baar K, Williams T, Luo H, Ke H, Rehmann H, Taussig R, Brown AL, Kim MK, Beaven MA, Burgin AB, Manganiello V, Chung JH: Resveratrol ameliorates aging-related metabolic phenotypes by inhibiting cAMP phosphodiesterases. Cell 2012, 148:421-433.

92. Dinkova-Kostova AT, Kostov RV: Glucosinolates and isothiocyanates in health and disease. Trends Mol Med 2012, 18:337-347. 
93. ClinicalTrials.gov homepage [www.clinicaltrials.gov].

94. Park JH, Kim JW, Lee CM, Kim YD, Chung SW, Jung ID, Noh KT, Park JW, Heo DR, Shin YK, Seo JK, Park YM: Sulforaphane inhibits the Th2 immune response in ovalbumin-induced asthma. BMB Rep 2012, 45:311-316.

95. Kong JS, Yoo SA, Kim HS, Kim HA, Yea K, Ryu SH, Chung YJ, Cho CS, Kim WU: Inhibition of synovial hyperplasia, rheumatoid T cell activation, and experimental arthritis in mice by sulforaphane, a naturally occurring isothiocyanate. Arthritis Rheum 2010, 62:159-170.

96. James D, Devaraj S, Bellur P, Lakkanna S, Vicini J, Boddupalli S: Novel concepts of broccoli sulforaphanes and disease: induction of phase II antioxidant and detoxification enzymes by enhanced-glucoraphanin broccoli. Nutr Rev 2012, 70:654-665.

doi:10.1186/ar4167

Cite this article as: Gray SG: Perspectives on epigenetic-based immune

intervention for rheumatic diseases. Arthritis Research \& Therapy 2013, 15:207. 